\title{
ETNICIDADE MARGINALIZADA: A IDENTIDADE HURRITA
}

\section{Priscila Scoville $^{l}$}

\begin{abstract}
Resumo: Pensar questóes de etnicidade pode contribuir muito para entendermos as populações do mundo antigo. O Oriente Próximo foi caracterizado pela predominância de grupos semitas e, em menor grau, indoeuropeus, mas esses não eram os únicos na região. Este artigo, portanto, pretende apresentar os hurritas, com um breve levantamento histórico e historiográfico baseado na etnicidade. Vivendo, durante anos, às margens da sociedade próximo-oriental, os hurritas mantiveram seus elementos étnicos e, no segundo milênio AEC, os fortificaram e dispersaram, formando o reino de Mitani. Graças a unificação dos grupos hurritas, decorrente do surgimento do reino, os elementos étnicos foram aceitos na região. Este estudo, então, apresenta uma discussão sobre a pesquisa de etnicidade, tanto na relação teórica como, em especial, no caso aplicado aos hurritas, para entendermos a dispersão e a identidade desses grupos.
\end{abstract}

Palavras-chave: Hurritas, Mitani, etnicidade, Antigo Oriente Próximo.

Ao norte da Mesopotâmia, grupos hurritas foram unificados no século XVI AEC sob a forma do reino de Mitani. O reino e sua população ainda são alvo de muita discussão na Academia, tanto em relação ao seu carácter étnico como a sua própria formação (espacial e política). No presente artigo, então, procuro apresentar alguns aspectos e debates sobre a identidade deste grupo, que, como afirma Liverani, era marginalizado até a unificação mitânia e consequente fortificação do elemento hurrita na antiguidade (LIVERANI, 2016, p. 405).

A predominância de comunidades semitas, sumérias e indo-europeias no Antigo Oriente Próximo, porém, não é o único motivo para a discreta aparição desse grupo na historiografia. Por muito tempo, os hurritas permaneceram à margem, também, dos estudos acerca da antiguidade, seja pela ação "política" dos estudos históricos (em que prevalecem grupos ocidentais), seja pelas suas fontes esparsas. No Brasil, isso se torna particularmente verdadeiro na medida em que pesquisas de antiguidade oriental estão voltadas, em especial, 
aos grandes nomes: acadianos, sumérios e, também, egípcios. Nesse sentido, grupos com fontes mais dispersas, como os hurritas, acabam sendo "esquecidos" nas pesquisas do país. Este trabalho, portanto, pretende contribuir com os estudos da antiguidade próximo-oriental, apresentando características étnicas e históricas deste grupo que teve sua existência suprimida pela prevalência de seus contemporâneos.

\section{O que é etNicidade e Como Pensá-la no mundo ANTigo?}

O conceito de etnicidade é empregado na História para pensar-se os aspectos culturais próprios de um grupo, a exemplo de costumes e linguagem. Contudo, a proximidade dos debates entre raça e etnia resulta em muitas críticas a este último termo, lhe sendo conferido um caráter pejorativo em muitos casos (cf. POUTIGNAT; STREIFF-FENART, 2011, pp. 33-54). Deste modo, começo este trabalho expondo o conceito, na esperança de proporcionar uma visão mais positiva sobre ele, que, em muito, pode contribuir para os debates sobre a antiguidade.

O que, então, é a etnicidade? Segundo Jenkins, é uma ampla categoria de análise simbólica que se baseia na diferenciação (do indivíduo ou do coletivo) e representa questóes políticas e culturais (produzidas e reproduzidas na interação social). Assim, a identidade de um grupo é formada pela comparação, que diferencia as práticas de cada povo. Os indivíduos (ou grupos) se identificam de uma maneira e os indivíduos (ou grupos) externos aos primeiros, os identificam de algum outro modo. A união dessas duas definições (interna e externa) é o que define uma etnia, que pode ser individual ou coletiva (JENKINS, 1998, pp. 40-56). Ainda neste sentido, Buccelatti afirma que:

Indivíduos reconhecem a si próprios como membros de um grupo e assim o são reconhecidos por aqueles de fora deste grupo. Postularemos posteriormente questões em relação as dimensões do fenômeno histórico e historiográfico - como isso realmente se moldou em dados momentos do passado, como isso é reconhecido com tanto recuo no tempo, e como isso pode ser aplicado em um sitio arqueológico específico (BUCCELLATI, 2010, p. 82).

Assim, elementos como a língua, religião, arte e costumes podem nos revelar as ligaçóes étnicas dos indivíduos do passado, ainda mais se pensarmos na relação dinâmica das cidades-estado na Antiga Mesopotâmia. Resulta 
dessa interação ativa entre os povos mesopotâmicos uma partilha de algumas características, tanto políticas como religiosas. Por isso, as identidades na região, aos olhos desatentos, podem facilmente ser confundidas. Como afirma Pinto, é comum historiadores utilizarem a palavra "etnicidade" como um termo técnico para "identidade", mas este implica em uma identificação psicológica e aquele aponta construções sociais e culturais divididas por um grupo específico. Nesse sentido, a identidade é algo mais pessoal, enquanto a etnicidade implica em uma formação social (PINTO, 2016, pp. 11-12). Os conceitos, porém, caminham próximos: uma identificação individual responde ao seu meio social, variando e se adaptando conforme o espaço físico e as etnias ao seu redor.

Se emprestarmos a discussão proposta por Estevez, ao refletir sobre a dinâmica entre cristãos e muçulmanos medievais, podemos perceber que a ideia de fronteira é muito mais fluída do que parece. No mundo pré-moderno, a noção de Estado-Nação não existe e a relação dos povos era algo muito mais ligado à sua etnicidade e a esfera de influência ao seu redor. Isso significa que os limites entre as cidades (e reinos) eram um espaço de circulação de ideias e tendências e, por isso, mais do que uma zona física, a fronteira gera relaçóes sociais, sendo um centro de intercâmbios culturais e da propagação deles (ESTEVEZ, 2012, pp. 23-26).

Uma delimitação geográfica, portanto, não é suficiente para especificar a etnicidade de um povo antigo. Pelo contrário, é a união de diversos elementos que auxilia para a nossa identificação e designação de um grupo específico. A etnicidade, enquanto constituinte de uma vida social, possibilita que indivíduos se liguem uns aos outros, dividindo crenças, origens, história e aspectos culturais, o que denota um senso de identidade no qual esses indivíduos pertencem a um grupo (SCHNEIDER, 2010, p. 143). Este grupo, como visto anteriormente, se diferencia dos demais, criando a dicotomia entre o "nós" e o "outro". Essa relação social e individual nos ajuda a pensar as formas de integração, interação e as diferentes visões de mundo na História Antiga, podendo, assim, contribuir em diversos âmbitos. A investigação da antiguidade, a partir de um viés etnográfico, em conjunto com a linguística (entendida como uma categoria étnica), tornou possível a própria descoberta dos grupos hurritas, no século XIX, por exemplo. Desde então, a Academia empresta pesquisas da Arqueologia, da Filologia e da Assiriologia, por exemplo, para definir este grupo. 


\section{O DEBATE SOBRE OS POVOS HURRITAS E DO NORTE MESOPOTÂMICO}

Em meados do século passado, Gelb lançou uma obra que apresenta discussóes acerca dos grupos hurritas e subarianos ${ }^{2}$. Apesar de sua primeira edição datar de 1944, o resultado do trabalho de Gelb ainda é bastante relevante para os estudos, uma vez que reúne informações sobre toda a documentação descoberta até então. Segundo o autor, os primeiros debates surgiram na tentativa de identificar o termo Šu-ba-ri-i (e Subartu), que aparecia em algumas inscrições cuneiformes (GELB, 1973, pp. 1-2). Neste primeiro momento, procurava-se entender os grupos subarianos, que, pouco depois, foram aproximados dos hurritas. Com isso, buscou-se saber se ambos correspondiam a um mesmo grupo étnico, cabendo a Gelb apontar essa resposta. Anos mais tarde, em 1989, Wilhelm lançou seus estudos que tratam especificamente dos povos hurritas.

Os hurritas começam a receber fontes mais propícias para sua identificação em 1887, quando descobriu-se uma coleção de tabletes com correspondências recebidas pelos reis egípcios (chamadas de Cartas de Amarna), entre as quais quatorze vinham do território de Mitani e uma (EA24) estava escrita em uma língua desconhecida ${ }^{3}$. A princípio, essa descoberta colocou outro grupo étnico em jogo, os mitânios, que até a descoberta dos documentos de Boğazköy ${ }^{4}$ eram considerados hititas ${ }^{5}$.

Os achados de Boğazköy encorparam ainda mais os debates. As escavações nesta cidade começaram em 1906 e logo trouxeram resultados. De acordo com Gelb, as pesquisas apontavam que algumas cartas deste corpus não mostravam relação com línguas semitas (como o acadiano), indo-

2 Subarianos, de acordo com o English Oxford Living Encyclopedia, correspondem a alguns grupos viventes na Mesopotâmia, numa região chamada Subartu, entre o terceiro e primeiro milênios AEC. Pode se referir, também, a língua falada por eles. Normalmente são relacionados aos Hhurritas, mas podem ser relativos a Assírios. Isso porque Subartu, posteriormente passou a pertencer a Assíria.

3 A versão em português destas cartas pode ser vista em: SCOVILLE, Priscila. Queremos nos amar como irmãos: uma análise historiográfica das cartas de Amarna e das relações entre Egito e Mitani entre c. 1390 - 1336 AEC. Dissertação de Mestrado. Curitiba: UFPR, 2017, pp. 168-214.

4 Antiga Hattusa, hoje também chamada de Boğazkale.

5 É importante ter em mente, porém, que existia uma diferenciação entre hititas (da Anatólia) e mitânios, chamados de Teshub-Hititas pela aproximação com o deus Teshub. Os documentos de Boğazköy, porém, mudaram esse panorama e o termo "hitita" passou a corresponder somente aos habitantes da Anatólia. 
europeias (como o hitita) ou o sumério, mas com o urartiano ${ }^{6}$. Do mesmo estudo, ainda, perceberam-se semelhanças nas linguagens usadas nas cartas enviadas de Mitani ao Egito com a de regiões do Cáucaso moderno (GELB, 1973, p. 5). Mais do que isso, as evidências de Boğazköy trouxeram luz a um grupo chamado de "as pessoas de Hurri", as "terras de Hurri" e o "inimigo hurrita” (WILHELM, 1989, pp. 1-2; MARTINO, 2014, p. 62-63). Outras descobertas, como os textos de Nuzi e de Ugarit, também apresentam aspectos de caráter linguísticos para pensarmos esses grupos. Os documentos de Nuzi, por exemplo, refletem uma sintaxe hurrita, apesar de estarem escritos em babilônico médio (LION, 1998, s/p) e de Ugarit possuímos uma série de rituais e hinos religiosos hurritas descritos em tabletes (WEST, 1994).

À primeira vista, esses documentos (de Amarna, Boğazköy, Nuzi, Ugarit, etc.) não parecem conexos, contudo, nosso entendimento atual sobre os grupos que habitavam o norte da Mesopotâmia e da Síria, deve muito a essa sequência de achados arqueológicos e debates. De forma breve, podemos afirmar que a discussão se deu muito no âmbito linguístico.

Uma vez que o termo hitita foi descartado para a identificação, sobraram os "subarianos", "mitânios" e "hurritas" para referir-se a língua utilizada nos escritos. Mitani, de acordo com Gelb, foi provada como sendo um território e não um elemento linguístico já em 1909 (GELB, 1973, pp. 4-5). De fato, o termo "mitânio" não aparece mais como um designador linguístico, mas muito ainda será debatido sobre ele (como veremos em momentos seguintes).

Por fim, então, a língua que aparece nos achados arqueológicos se volta ao debate do subariano e hurrita. Por um lado, as correspondências de Boğazköy atestam uma língua identificada como "hurrita"; por outro, alguns achados acadianos apontam para uma identificação com Subartu, tida como subariana. Não demorou muito, porém, para que esta última opção fosse descartada. As análises filológicas indicaram que os termos utilizados eram uma expressão acadiana e que não significavam, necessariamente, que a língua era subariana, apenas que era utilizada em uma região, chamada de Subartu, onde hurritas e acadianos poderiam ter coexistido (GELB, 1973, pp. 12-13). Outro fator que contribuiu para uma identificação hurrita é o fato de que, não somente os

\footnotetext{
$6 \mathrm{O}$ urartiano, também chamado de vânico, era a língua oficial do território de Urartu, no norte da Anatólia. A língua não é de origem indo-europeia e acredita-se que descenda de uma língua da família hurrita. Esse reino esteve na região entre os séculos IX e VI AEC, sendo, portanto, posterior a ocupação hurrita. Segundo a enciclopédia britânica, Urartu se expandiu (apesar se não se centrar) pela região da transcaucásia, da Rússia moderna ao noroeste do Irã e, em alguns momentos em partes do nordeste sírio (URARTIAN language. Encyclopæedia Britannica. 02 de novembro de 2015. Disponível em: https://www.britannica.com/topic/Urartian-language).
} 
hititas utilizavam o termo, mas os próprios grupos do norte mesopotâmico e sírio se auto designavam hurritas (como atestado nos documentos de Amarna e Nuzi, por exemplo).

$\mathrm{O}$ debate sobre a origem daquela língua estranha (que não era nem semita, nem indo-europeia), encontrada entre o final do século XIX e início do XX, em documentos de variadas regióes, enfim, pôde se definir: era hurrita. Essa percepção é importante, uma vez que

Ser um falante nativo de uma determinada língua é, na maioria dos casos, a característica primária de identidade étnica. A razão para a distinção da língua nativa é que ela é o sinal menos transparente: ela é uma verdadeira cifra, uma que só pode ser decifrada por aqueles que dividem o código [...]. Disso emerge um senso de quase cumplicidade, que enfatiza a barreira entre "nós" e "os outros", especialmente em uma configuração multiétnica (e multilinguística) (BUCCELLATI, 2013, pp. 84-85).

Uma aproximação linguística pode nos servir de ponto de partida para entendermos as características e a dispersão dos povos falantes do hurrita. A discussão sobre a identidade de desses grupos ainda está longe de ser finalizada, mas algumas balizas foram conquistadas desde as primeiras descobertas. É possível perceber a disseminação da língua e, possivelmente, de pessoas que se identificam como hurritas, atestando a presença de nomes hurritas em diversas cidades antigas, como Urkesh (atual Tall Mozan) e Ugarit (atual Ras Shamra). Estudos voltados aos nomes hurritas são propostos, por exemplo, por Van Soldt e Buccellati, respectivamente, sobre as regióes de Ugarit, com documentos escassos, e Urkesh, onde as fontes são mais abundantes neste sentido ${ }^{7}$.

Uma outra maneira de identificar essa dispersão e conseguir caracterizar os hurritas de modo étnico é por meio de elementos religiosos. Isso porque, assim como a língua, práticas e crenças ajudam a criar uma consciência agregadora dos povos hurritas - ainda que eles não estejam politicamente unificados. Além disso, como aponta Buccellati, a religião é um elemento ainda mais transparente e tangível ao exterior, pois incorpora tanto as ações individuais ou rituais, como os objetos e as edificações (BUCCELLATI, 2013, p. 86).

7 As obras em questão são BUCCELLATI, Giorgio. When Were the Hurrians Hurrian? The Persistence of Ethnicity in Urkesh. In: ARUZ, Joan; GRAFF, Sarah B.; RAKIC, Yelena (eds). Cultures in Contact. From Mesopotamia to the Mediterranean in the Second Millennium B.C. Nova York: Yale University Press, 2013, pp. 84-95 e VAN SOLDT, Wilfred. The use of Hurrian Names at Ugarit. Ugarit-Forschungen, 35, 2002, pp. 681-707. 
A presença hurrita em Urkesh é atestada, ainda segundo Buccellati (2013, p. 85), desde o terceiro milênio AEC, sendo um dos primeiros centros hurritas conhecidos. As teorias mais aceitas atualmente, entretanto, apontam que a unificação de grupos hurritas só acontece no século XVI AEC. Isso significa que durante séculos os hurritas estiveram separados, podendo pertencer a um grupo fechado ou disseminar-se entre outros. Segundo Jarol, essa mescla entre hurritas e outros grupos étnicos em diversas cidades foi possível por um caráter pacífico relacionado aos hurritas, tido como um grupo fácil de se relacionar (JAROL, 1986, p. 31). Por outro lado, Bryce (2014, p. 34) os caracteriza como agressivos e expansivos, apontando isso como o motivo para a presença hurrita ser atestada de forma tão dispersa. $\mathrm{O}$ autor ainda afirma que um vácuo político, causado pelo fim do império acadiano, possibilitou a distribuição de grupos hurritas pelo leste mesopotâmico e a instalação de pequenos principados na região que permaneceram com relativa estabilidade por cerca de um século (BRYCE, 2014, p. 34-35). Nestas cidades alguns elementos permanecem com atributos tipicamente hurritas e, com isso, podemos estabelecer aspectos que caracterizam uma etnicidade hurrita.

Além da linguagem, já estabelecida anteriormente, temos, por exemplo, estruturas sacras que se mantêm sem alterações por mais de um século e ocupações em Urkesh que duram um milênio (BUCCELLATI, 2013, pp. 87-90). Por outro lado, em uma região dinâmica como o Antigo Oriente Próximo era, é normal que algumas interferências ocorram. Wilhelm aponta que a relação de mitos, crenças e deuses hurritas se muniu, em muito, dos grupos mesopotâmicos. Textos sagrados da literatura da Mesopotâmia teriam sido copiados por sacerdotes hurritas, que enriqueciam os escritos com uma identificação de seus próprios deuses com os outros (WILHELM, 1989, p. 49). Algumas divindades hurritas, porém, se destacam, em especial, o deus Tešub, que é referenciado em grande parte das referências hurritas.

Tešub aparece em fontes do Antigo Oriente Próximo desde o terceiro milênio AEC (WILHELM, 1989, p. 49), mas, neste momento, de forma bastante esparsa. Foi durante meados do segundo milênio AEC que seu nome se tornou mais proeminente e, não por coincidência, foi nesta época que os hurritas estiveram mais fortificados e unidos em uma estrutura política.

\section{A IDENTIFICAÇÃo das TERRAS E POVOS de Hurri E O CASO DE IDRIMI}

Se as fontes mencionam as "terras de Hurri", o próximo passo é identificar sua localização ou, ao menos, decifrar as regióes que foram habitadas por hurritas. Segundo Haas e Wilhem (1974, p.1) os primeiros vestígios hurritas 
encontrados na mesopotâmia são do terceiro milênio, predominantemente entre o Rio Tigre e as montanhas de Zagros. Eles aparecem, portanto, no norte e nordeste da Mesopotâmia, ainda durante o período acadiano, caracterizado pelas conquistas de Sargão. O local de origem desses povos, porém, ainda é desconhecido, havendo argumentos em favor da região da Transcaucásia e do leste da Anatólia (BRYCE, 2014, p. 34), apesar de haver certa predominância na defesa da primeira e, mais especificamente, na região da Armênia (ROUX, 1992, p. 234).

Independentemente da origem, a presença de grupos hurritas é percebida de forma bastante ampla, espalhada pelo norte da Mesopotâmia e da Síria e pelo leste da Anatólia (CANCIK-KIRSCHBAUM; BRISCH; EIDEM, 2014, p. 2), aparecendo em textos de Mari, Emar e Ugarit, por exemplo (BIENKOWSKI; MILLARD, 2000, p. 150), em especial, nos momentos pós-Sargão.

Alalakh e Nuzi são outros exemplos dessa distribuição hurrita, uma vez que ambas cidades apresentam documentações deste grupo e estão geograficamente distantes: a primeira se encontra atualmente no sul da Turquia (moderna Tell Atchana) e a segunda no Iraque (moderna Yorghan Tepe). A maioria da população de Nuzi possui nomes hurritas (BIENKOWSKI; MILLARD, 2000, p. 216) e a documentação nos traz informações sobre a economia e a sociedade deste grupo étnico. Alalakh, por sua vez, nos ajuda a pensar o caráter político, em relação a sua organização e estruturas de dominância.

$\mathrm{O}$ nome Nuzi foi conferido à antiga cidade de Gasur no momento da ocupação desta por hurritas, em c. 1700 AEC (ROUX, 1992, pp. 234235). De Nuzi, possuímos diversos textos que, apesar de estarem escritos em acadiano, nos revelam sobre um grupo étnico que não era semita. $\mathrm{O}$ acadiano falho, usado nos documentos oficiais, mantinha relações com o dialeto local - o hurrita. Poucos escribas dominavam completamente o acadiano e, enquanto a escrita se mantinha semita, a língua falada na vida cotidiana era o hurrita. Isso significa que as inscrições oficiais possuíam vocabulário, morfologia, sintaxe, ortografia e fonologia hurritas, ainda que escritas em acadiano (BERKOOZ, 1937, p. 5). Exemplo disso é o uso da expressão hurrita helahelumma epēšu ao invés do acadiano eserta esēru para referir-se ao casamento de concubinas ou esposas de classe menor (PARADISE, 1987, nota 37).

Não são apenas os textos e a recorrência de nomes hurritas, porém, que nos apontam para a presença deste grupo étnico em Nuzi. Artefatos cerâmicos possuem algumas características próprias que são relacionadas aos hurritas. A princípio, os hurritas adotaram a língua e os costumes dos semitas habitantes de Nuzi, construindo, ainda assim, uma comunidade hurrita bastante próspera. 
Contudo, a partir de cerca de 1600 AEC, padróes e elementos hurritas com começaram a prevalecer nas cerâmicas das cidades ocupadas no vale do rio Khabur (do norte da Síria ao norte mesopotâmico) (ROUX, 1992, p. 235). As cerâmicas antes pintadas de modo bastante simples, com traços horizontais e formas geométricas monocromáticas, passam a se caracterizar pela presença de elementos da fauna e da flora, possuindo traços curvos e delicadamente pintados (STEIN, 1984). Apesar de ser chamada de "produto de Nuzi (Nuzi Ware)", esse tipo de cerâmica foi encontrado tão longe quanto Alalakh, sendo seu nome apenas uma referência ao local de sua descoberta ${ }^{8}$.

Além das cerâmicas e de textos com relações hurritas, em Alalakh foi encontrada a estátua de Idrimi $^{9}$ (fig.5), datada do século XVI AEC, que contém inscrições muito interessantes sobre a dinâmica entre grupos do Antigo Oriente Próximo. Contudo, antes de nos dedicarmos a uma análise sobre o texto, destaco um aspecto estilístico dessa estátua, que nos ajudará a pensar em Idrimi e sua identificação com o povo hurrita.

No trabalho de Buccellati (2013) aponta-se o uso de ornamentos para a cobertura da cabeça como parte de um repertório étnico hurrita. São exemplos as figuras a seguir:



Dossiê

Figura 1: Cabeça de homem em argila cozida (BUCCELLATI, 2013, pp. 91-92).

8 A obra de Stein (1984), dedicado às cerâmicas de Khabur e Nuzi, apresenta uma discussão sobre o nome Nuzi Ware, conferido a esse tipo de cerâmica, colocando pontuações acerca de sua relação hurrita.

9 Atualmente no British Museum, sob número de catálogo 130738. Disponível em: http://www.britishmuseum.org/research/collection_online/collection_object_details. aspx?objectId $=368128 \&$ partId $=1 \&$ searchText $=$ idrimi $\&$ page $=1$ 



Fig. 2: Impressão de selo cilíndrico do período Acadiano (BUCCELLATI, 2013, pp. 91-92).

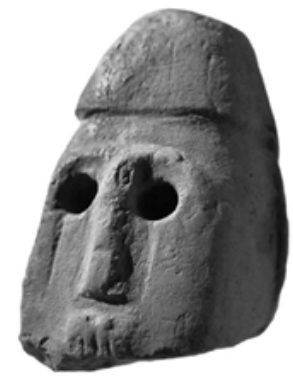

Fig. 3: Cabeça de homem em pedra (BUCCELLATI, 2013, pp. 91-92).

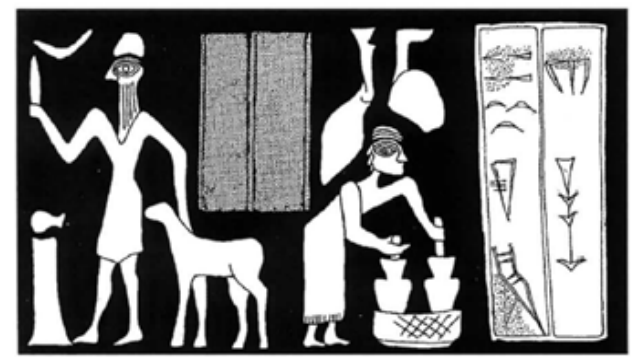

Fig. 4: Impressão de selo cilíndrico do primeiro selo de Tuli (BUCCELLATI, 2013, pp. 91-92).

Faz parte de uma identificação hurrita o uso de adereços na cabeça e, para além disso, tipos de vestimenta específicos. As Cartas de Amarna nos sugerem a existência de um padrão de moda, tendo Tušratta enviado ao Egito roupas no estilo hurrita, como vemos na EA27 (linhas 110-111): "[Agora como se]us [presentes, uma] camiseta estilo hurrita, uma camiseta estilo urbana, um robe, uma pedra [preciosa], [um par]a a mão com pedras-"olho" de genuína pedra hulalu, cinco \{por corda\}, cravadas em ouro..." (SCOVILLE, 2017, p. 199).

Para Idrimi isso não é diferente: sua estátua possui um adorno parecido com o da imagem da cabeça de pedra (fig. 3). Por coincidência, ou não, ambas as peças (fig.3 e fig.5) são datadas do período de Mitani, ainda que Idrimi seja do início da formação desse reino e a cabeça não possua uma data específica. 

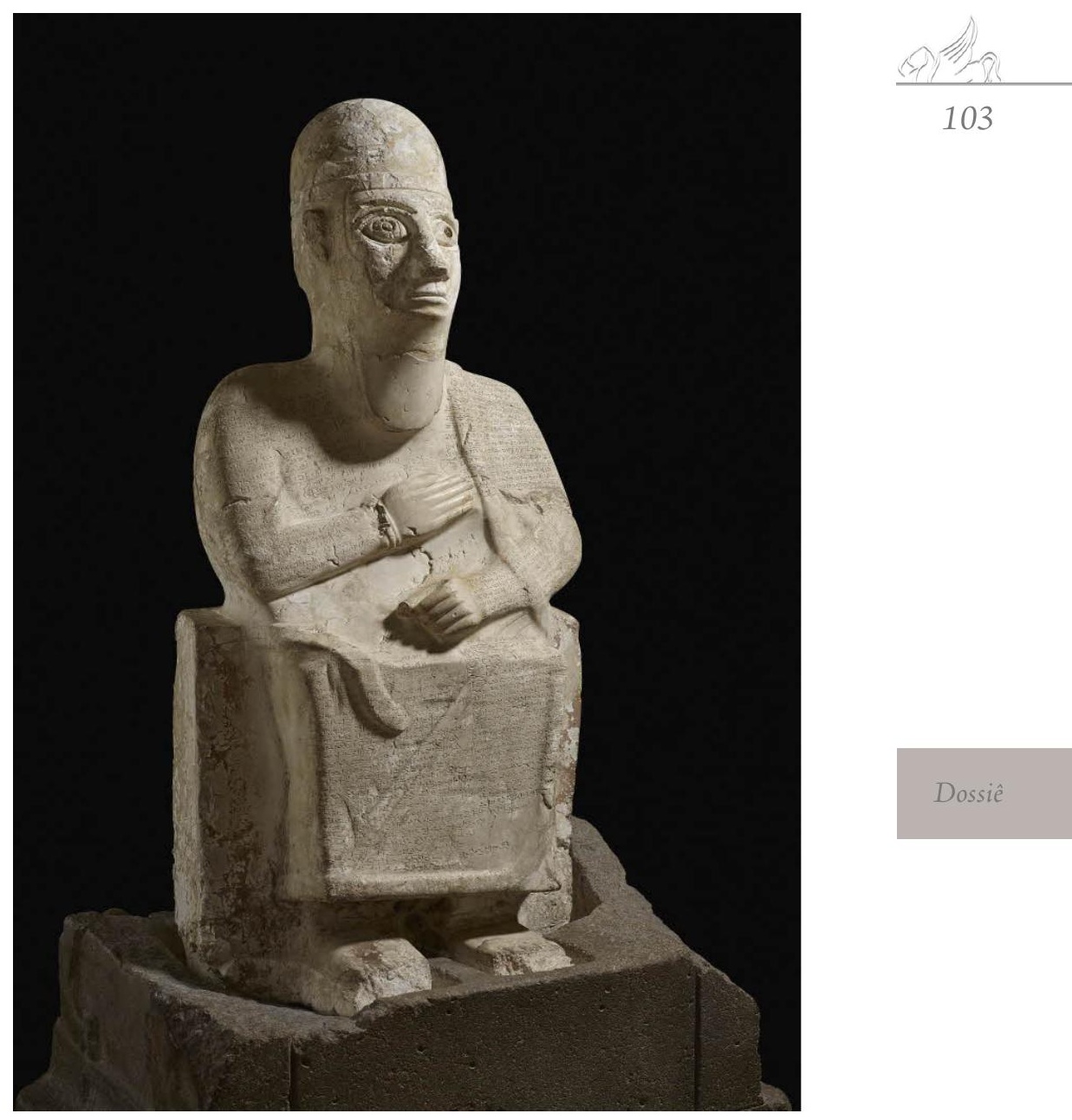

Fig.5: Estátua de Idrimi, rei de Alalakh.

Fonte: British Museum Website. (C) The Trustees of the British Museum

A estátua de Idrimi ainda nos traz outros elementos sobre a identificação deste rei de Alalakh com os hurritas. Esses aspectos são perceptíveis nas inscrições que percorrem seu corpo (fig.6). O texto começa: "Eu sou Idrimi, o filho de Ilimilimma, servo de Tešub, Hebat e Šauška, a senhora de Alalakh, minha senhora" (KUHRT, 1995, p. 289. Tradução da autora). Ou, em sua forma transliterada: "a-na-ku id-ri-mi DUMU (mār) DINGIR (Ilim)-i-limma IR (arad) IM (Adad/Tešub) He-bat ù Ištar NIN (bēlet) URU (āl) A-la-lah NIN (bēlti)" (GREENSTEIN; MARCUS, 1976, p. 64). 
Neste momento, é interessante apontar que os nomes em sua forma transliterada não são exatamente os mesmos da tradução, como é visível. Por isso, chamo a atenção para o fato de que os deuses do Oriente Próximo, muitas vezes possuíam equivalentes em outros panteóes. Hebat é uma deusa hurrita e sua contraparte é Tešhub, equivalente de Adad (semita). Ištar, por sua vez, é a equivalente semita da hurrita Šauška. O cuneiforme usado para a escrita na estátua é predominantemente acadiano, com influência visível do hurrita. Por isso, os nomes de deuses variam, sendo, em alguns casos, apresentados pelo seu equivalente semita.

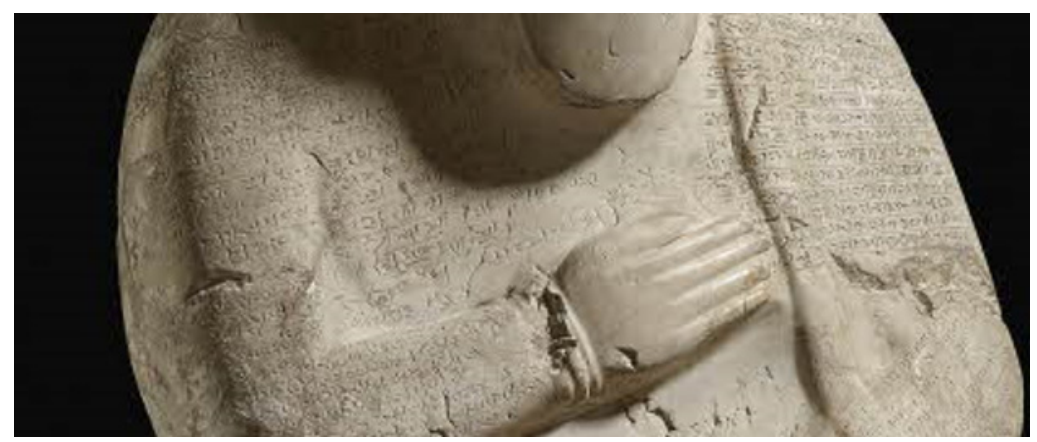

Fig. 6: Detalhe da estátua de Idrimi, rei de Alalakh.

Fonte: British Museum Website. (C) The Trustees of the British Museum.

Se pensarmos, então, na influência linguística hurrita no texto (ainda que escrito em acadiano), podemos entender que intencionalmente os deuses mencionados na estátua seriam hurritas ${ }^{10}$, sendo a equivalência acadiana correspondente ao tipo de escrita predominante. Deste modo, uma deusa hurrita, Šauška, é apresentada como a padroeira da cidade de Alalakh. É conveniente notar, porém, que Idrimi não é proveniente de Alalakh, mas de Halab (atual Aleppo), na Síria. Nas inscrições, Idrimi aponta que, após conflitos em sua cidade natal que o tornaram um exilado político, sua família viveu em Emar (atual Tell Meskene), também na Síria, e pouco depois ele foi

10 Uma tradução mais antiga coloca os deuses não hurritas Adad, Hepat e Ishtar, ao invés de Tešub, Hebat e Šauška [PRITCHART, 1969, pp. 557-558]. Essa tradução, segue a leitura acadiana do texto. Porém, acredito que a versão de Amélie Khurt (utilizada neste trabalho), apresenta melhor as intenções de escrita. Isso porque o cuneiforme acadiano foi adotado para a escrita hurrita e, por mais que o texto esteja, então, em acadiano, o seu autor possivelmente era hurrita (isso é perceptível pelo mau uso da língua semita e a presença de sintaxe hurrita no texto) - consequentemente, sua crença deveria ir de acordo com isso. 
ainda mais ao sul, convivendo com pessoas de várias regiões, antes de ir até Alalakh.

O texto não nos revela quais foram as circunstâncias dos conflitos ocorridos em Halab quando Idrimi e sua família tiveram que fugir. As pesquisas tendem a apontar as investidas do rei hurrita Parattarna como o possível motivo da fuga (PODANY, 2010, 135). A cidade, porém, se localiza em um território bastante disputado por hititas e hurritas. $\mathrm{O}$ texto hitita $A$ Proclamação de Telipinu nos sugere esses conflitos: "Ele [Muršili I] foi para a cidade de Halpa [Halab], destruiu Halpa e trouxe os deportados de Halpa (e) seus bens para Hattusa. Então, depois ele foi para a Babilônia, ele destruiu a Babilônia e lutou contra (tropas) hurritas" (VAN DEN HOUT, 2003, p. 195. Tradução da autor).

Os conflitos no norte da Síria são respostas às expansões hitita e hurrita - esta última, além de ampliar suas fronteiras, estava, também, se fortificando em uma unidade política. A estátua de Idrimi nos ajuda a pensar essa unificação e consolidação hurrita. No texto descreve-se alguns eventos que aconteceram durante a vida de Idrimi enquanto refugiado, contudo, destaco a referência ao rei Parattarna, de Mitani, ao qual Idrimi teria jurado lealdade, garantindo sua posição de rei em Alalakh. Ele diz:

Por sete anos Parattarna, o poderoso rei, rei dos hurritas, foi hostil a mim. No sétimo ano, eu enviei a Parattarna, o rei, o rei dos hurritas, Anwanda e o disse sobre o esforço de meus antepassados: que meus antepassados tinham se aliado, que nossos ancestrais eram aceitos pelos reis dos hurritas e eles tinham feito um poderoso juramento entre eles. $\mathrm{O}$ poderoso rei ouviu sobre o esforço de nossos ancestrais e o juramento mútuo e estava receoso com o conteúdo do juramento. Por causa das palavras do juramento e por causa de nossos esforços, ele aceitou meu presente. No mês de Kinunu, eu fiz extensivas libações. Assim, eu trouxe a ele novamente a casa que estava em luta. Na minha nobreza, na minha lealdade, eu jurei amizade a ele. Assim, eu me tornei o rei de Alalakh. (KUHRT, 1995, p. 91. Tradução da autora).

Neste trecho, Idrimi aponta desavenças entre os reis hurritas, mas que, diante de um juramento de lealdade, puderam ser superadas. Parattarna, o rei dos hurritas, é um dos primeiros reis de Mitani de que se tem referência, sendo o primeiro a possuir vestígios diretos de seu reinado. Anteriormente a ele conhecemos os nomes Kirta e Shuttarna I - do primeiro não há 
qualquer evidência ${ }^{11}$ e do segundo possuímos um selo real, mas que foi usado posteriormente. Não é de se estranhar que o momento fosse tumultuoso, afinal, um grupo estava ainda nos caminhos iniciais para unificar todos os hurritas do norte mesopotâmico. Deu certo. Os hurritas passaram a pertencer ao reino de Mitani, com chefes locais, tais como Idrimi, auxiliando na administração, manutenção e expansão do território - especialmente no que diz respeito aos embates contra os hititas.

\section{Os hurritas de Mitani}

Conforme foi comentado no decorrer deste trabalho, Mitani é a designação política de um reino formado por meio da união dos povos hurritas no norte da Mesopotâmia ${ }^{12}$. A formação e o caráter étnico de Mitani, porém, ainda são muito discutidos. Parte disso acontece por causa da carência de fontes provenientes do reino mitânio, nos sendo disponíveis apenas referências externas (FREU, 2003, p. 15). Consequentemente, aspectos internos que podem nos apresentar informaçóes relevantes sobre a identidade e a ideologia dos habitantes e governantes desse reino são escassos. Assim, a questão sobre a de identidade de Mitani é debatida por diversos autores e ainda não foi superada.

Um primeiro problema, apontado por Garelli, é saber se existiam dois reinos, Hurri e Mitani, ou se ambos são o mesmo (GARELLI, 1982, p. 308). Inicialmente, baseando-se na pesquisa de Goetze, acreditava-se que Hurri e Mitani eram dois reinos separados, pois Mitani não teria sido capaz de unificar todos os grupos (GOETZE, 1957, pp. 67-68). Atualmente, porém, a teoria mais aceita defende que Hurri é um identificador étnico de um reino chamado Mitani. Assim, Hurri e Mitani são nomes que representam um mesmo local, que pode ser apresentado de duas formas: pela realidade étnica (Hurri) e pela qualidade política (Mitani).

\footnotetext{
11 Existe uma referência de Ugarit, um poema chamado de "Épico de Kirta" ou "Lenda de Keret", que narra a história e as conquistas de Kirta. Segundo Pardee [2013], o autor da tradução em inglês deste épico, a história narrada não parece ter origem ugarítica, sua origem e datação ainda não foram definidas. Pardee ainda afirma que a cópia feita em Ugarit pode ter sido usada como instruções de aprendizado sobre como reis e deuses devem se relacionar. Sabemos hoje, porém, que Ugarit foi uma cidade que sofreu influência hurrita e, sendo Kirta um rei hurrita ou não (isso se ele tiver de fato existido), o poema pode ter se tornado uma espécie de base legitimadora para os reis hurritas. Shuttarna I afirma ser filho de Kirta, talvez de uma forma simbólica para corroborar seu papel de rei e fortificar as bases do recém-formado reino de Mitani. Nesse caso, o primeiro rei de Mitani pode não ter sido Kirta, mas Shuttarna I.
}

12 O trabalho de Novák (2014) apresenta a dimensão do império de Mitani. 
Contudo, apesar da população hurrita, análises linguísticas propõem uma dominação de grupos indo-arianos ${ }^{13}$ no reino de Mitani. Diversos autores apontam para o fato de que os nomes dos governantes podem ser explicados por meio dos Vedas: Artatama (Rta-dhāma: "aquele cuja residência é a lei divina"); Parsashatar (Para-sastar: "o que castiga os inimigos"); e Tušratta (Tuiš-ratta: "o que possui o carro de esplendor) ${ }^{14}$ (GARELLI, 1982, p. 144; WILHELM, 1989, p. 18). Além disso, documentos hititas apresentam deuses indo-arianos, como Mitra, Varuna, Indra e os Nasatyas, no panteão de Mitani ${ }^{15}$. Contudo, a importância dada aos deuses hurritas ainda é maior (PODANY, 2010, p. 155) e, entre a população, a presença de nomes hurritas é esmagadora - conforme atestado em cidades como Alalakh, Qatna, Tunip, Ugarit e Nuzi (GARELLI, 1982, p. 144).

Entre as explicações propostas sobre a formação de Mitani, afirma-se que é possível que reino não tenha se originado por uma população indo-ariana recém-chegada nos territórios hurritas, mas por descendentes, falantes de uma língua parecida com o sânscrito (PODANY, 2010, p. 154; e FREU, 2003, pp. 16-17), porém, apenas uma pequena parte do vocabulário e verbos indoarianos foram incorporados na língua hurrita (VON DASSOW, 2014, pp. 12 13), a exemplo do termo mariyannu (mariyanni), que significa "jovem soldado": mariya vem do sânscrito e o sufixo -anni (-annu) é hurrita (PODANY, 2010, pp. 154-155; VAN DE MIEROOP, 2007, p. 123). Até o momento, desde modo, não podemos afirmar como acontece essa influência indo-ariana, seja por descendência, por algum grupo direto ou por uma influência de terceiros.

A data para a unificação dos povos hurritas é outra questão de debate. Duas das hipóteses mais comuns são próximas. Para a primeira, Mitani já teria se formado e fortificado no final do século XVII AEC ou início do XVI AEC; para a segunda, a implementação de Mitani só acontece no final século XVI AEC (MARTINO, 2014, pp. 65-68). Não cabe, neste estudo, apresentar os argumentos de cada teoria, mas convém dizer que acredito na segunda, baseada pela quantidade de títulos de reis hurritas ${ }^{16}$ deste momento e na ausência do topônimo "Mitani" nos períodos anteriores. Nesse sentido, acredito que durante o século XVI AEC os grupos hurritas ainda estavam em

13 Outras teorias apontam para que não tenha havido uma presença indo-ariana, mas uma influência que se tornou uma tradição com o decorrer do tempo.

14 Garelli ainda aponta para exemplos de nomes vindos das cidades de Kadesh e Damasco.

15 Essas divindades podem ser vistas em cartas hititas, como a KBo 1.1. Traduzida, em inglês, em: BECKMAN, Gary M. Hittite Diplomatic Texts. Atlanta: Scholars Press, 1996, pp. 37 - 50.

16 Apresentados na KBo III 60. 
fase de unificação, formando e fortificando alianças (tendo Idrimi como um exemplo disso) e, somente no final do século, esses grupos estavam unificados sob forma de um reino.

Independentemente do caso, Mitani cresceu e tornou-se uma das maiores potências do Antigo Oriente Próximo, mas não durou muito. Estimase que cerca de trezentos anos tenham se passado entre sua fundação e a total fragmentação (quando o território foi dividido entre hititas e assírios). Freu [2003], divide a história de Mitani em seis momentos. O primeiro é o de formação, estimado entre c. 1560 e 1500 AEC. O segundo é de desenvolvimento do império (c. 1500 - $1450 \mathrm{AEC}$ ), que se seguiu por um momento de crise (c. 1450 - 1430 AEC). O apogeu de Mitani teria durado entre c. 1430 e 1340 AEC. Os últimos momentos, por fim, mostram a decadência, chegando ao final do império (c. 1340 - 1325 AEC), seguido pela dominação hitita e assíria (c. $1325-1260$ AEC).

Ainda que sua duração não tenha sido extensa, o reino de Mitani contribuiu para a dispersão e aceitação do pensamento hurrita e com tecnologias (como o carro puxado por cavalos, cuja invenção é atribuída aos mitânios $\left.{ }^{17}\right)$. O crescimento rápido do reino de Mitani acontece por investidas militares bem-sucedidas, o que parece se opor ao argumento de Jarol que coloca os hurritas como pacíficos por natureza e concordar com a ideia mais agressiva apresentada por Bryce, como visto anteriormente. Contudo, após o estabelecimento do reino, as políticas para sua manutenção focaram-se em alianças, tendo sido evitados confrontos militares.

Sabemos, por outro lado, que neste momento, os reinos do Antigo Oriente Próximo possuíam uma tendência pacífica, estando em uma era diplomática (a Era de Amarna ${ }^{18}$ ) marcada pela tentativa de manter alianças entres os Grande Reinos ${ }^{19}$. Entretanto, a teoria e a prática das relações entre os reinos não são necessariamente equivalentes. Hatti, por exemplo, apesar de participar dos acordos diplomáticos realizava frequentes ataques em regióes

17 Este comentário é feito por diversos autores, dos quais destaco VAN DE MIEROOP, Marc. A History of the Ancient Near East ca. 3000-323 BC. Oxford: Blackwell, 2007, p. 124; e COLINS, Paul. From Egypt to Babylon: the International Age 1500 - 500 BC. Cambridge: Harvard University Press, 2008, p. 24.

18 A relação da Era de Amarna e as negociações diplomáticas entre o Reino de Mitani e o Egito foram trabalhadas por mim durante o mestrado e podem ser vistas na dissertação decorrente dele, intitulada "Queremos nos amar como irmãos: uma análise historiográfica das cartas de Amarna e das relações entre Egito e Mitani entre c. 1390 - 1336 AEC".

19 Assíria, Babilônia, Egito, Hatti e Mitani. 
de fronteira e agrupava, entre os seus, grupos subordinados a outros reis ${ }^{20}$. Mitani, porém, não parece ter compactuado com esse tipo de atitude e a documentação que possuímos demonstra um esforço conciliador e pacífico, mantendo amizades e reforçando laços.

\section{ReFLEXóes FinAis}

Os arquivos de Amarna contam com diversas correspondências trocadas entre reinos antigos. Entre os documentos encontrados neste conjunto, estava a EA24, uma carta enviada pelo rei Tušratta ao Egito, escrita em uma língua estranha aos pesquisadores do final do século XIX e início do XX. Inicialmente, tal língua foi identificada como "mitânio", uma vez que Tušratta se identificava como rei de Mitani. Poucos anos depois, uma nova descoberta, em Boğazköy, trouxe à luz novos elementos para a discussão sobre como identificar àquela língua e os seus falantes: nos textos a língua era chamada de hurrita e fazia-se referência às "terras de Hurri" e ao "inimigo hurrita". Os debates buscavam identificar esse povo e não demorou para que os estudos o entendesse como um grupo étnico diverso. Diversos elementos contribuíram para estabelecer as características específicas dos hurritas, como a língua, a religião e as vestimentas - conforme apontado no decorrer deste artigo.

Por muito tempo, porém, os grupos hurritas não possuíram uma unidade política, estando dispersos em cidades pequenas ou entre outras etnias, em várias regiões do Antigo Oriente Próximo. Um dos primeiros centros hurritas foi Urkesh, de onde pesquisas arqueológicas possibilitaram o descobrimento de evidências que contribuíram para a compreensão de uma identidade hurrita. Contudo, cidades tipicamente hurritas não são comuns e a presença hurrita não parece muito relevante até o estabelecimento de Mitani.

Novas evidências, que nos ajudem a identificar as regiões habitadas por grupos hurritas, ainda podem ser encontradas pela arqueologia. Destarte, pelo que sabemos até os dias atuais, a quantidade de elementos culturais hurritas aumenta de forma expressiva por volta de 1500 AEC (KUHRT, 1995, p. 288), momento em que o reino de Mitani se estabeleceu, agregando territórios do norte da Síria, da Mesopotâmia e parte leste da Anatólia. A recorrência de vestígios hurritas em diversas cidades, ainda que de forma tímida, aponta a presença desses grupos desde o terceiro milênio. Assim, o crescimento do número de vestígios encontrados (datados do momento em que o reino de

20 Esses aspectos podem ser vistos em diversas cartas do conjunto de Amarna, com reis alertando sobre ataques e saques por parte dos hititas. 
Mitani surgiu), não parece ser consequência de um aumento populacional, mas uma resposta política, causada pela fortificação do elemento hurrita pela unificação dos grupos.

É interessante ressaltar, porém, que o mundo mesopotâmico possuiu uma predominância de povos de origem semita, indo-europeia e suméria e etnias estranhas a elas tornavam-se alheias ${ }^{21}$, colocadas à margem das sociedades locais. Com os hurritas, por muito tempo, isso não foi diferente. Somente a instalação de um reino poderoso, estabelecido como uma das cinco grandes potências $^{22}$ da segunda metade do segundo milênio AEC, possibilitou que o elemento hurrita tornasse-se tolerado e aceito neste mundo majoritariamente semita.

As primeiras discussóes sobre hurritas aparecem em torno de aspectos étnicos, como a linguagem e os costumes. As pesquisas, com o tempo, puderam se expandir, pensando nas relações históricas de origem e estabelecimento desse grupo e seu reino. Contudo, o desenvolvimento de estudos hurritas ainda pode partir dos debates étnicos, como acredito que este artigo tenha demonstrado. Discutir etnicidade nos auxilia a pensar não somente nas características de um povo específico, mas suas ligações e formas de interação com o mundo e com as pessoas ao seu redor.

21 A documentação, do ponto de vista linguístico, nos revela a presença de grupos semitas desde os primeiros registros de ocupação do crescente fértil. Outros grupos linguísticos entraram na região de forma posterior, em uma propulsão lenta e contínua. $\mathrm{O}$ tronco indo-europeu é o que mais se destaca entre esses novos atores, mas também há os elamitas, os sumérios e os hurritas, por exemplo (LIVERANI, 2016, pp. 57-58). Diversos grupos foram assimilados e suplantados ao decorrer dos anos. A predominância semita, porém, é inegável (ainda que dividida com uma predominância suméria). Isso ficou ainda mais expressivo quando Sargão da Acádia aumentou seu território, criando um poder imperial na Mesopotâmia. Quando Sargão se expandiu, a cultura semita (na qual se inclui o acadiano) prevaleceu. Contudo, a fragmentação do império de Sargão, causada pelos gútios, demonstra a existência de grupos periféricos que também possuíam pretensóes imperiais. Por outro lado, como afirma Liverani, a dominação dos gútios na Mesopotâmia, bem como a presença de outros grupos periféricos (como lullibi e hurritas), não deixa marcas profundas na forma de organização política e administrativa da região (LIVERANI, 2016, pp. 229-230). As línguas suméria e acadiana são as que apresentam vestígios mais antigos, estão a primeira ligada a Baixa Mesopotâmia e a segunda mais dispersa (sendo o Assírio e o Babilônico dois dos seus dialetos mais conhecidos). Foi o semita (acadiano), porém, que prevaleceu em textos oficiais e na recorrência de nomes próprios em algumas das maiores cidades mesopotâmicas (VAN DE MIEROOP, 2007, p. 34-35, 55). Nem somente a Acádia, entretanto, caracteriza os grupos semitas. Eles também são hebreus, cananeus, amoritas e fenícios, por exemplo. Isso demostra a expansão da cultura semita, ainda que dividida entre diferentes grupos. Essa dispersão possibilitou a predominância de muitos elementos, ao mesmo tempo em que se distancia e aliena os grupos menos expressivos - entre os quais estão os hurritas.

22 São elas Assíria, Babilônia, Egito, Hatti e Mitani. 
Pudemos perceber que, apesar de dispersos e sufocados entre outros, hurritas estiveram presentes na região mesopotâmica. Era difícil fazer com que uma cultura não-semita prevalecesse, ou sequer aparecesse entre as demais. Felizmente, graças aos vestígios e às análises linguísticas podemos encontrar elementos hurritas e perceber a importância de Mitani na difusão e fortificação desse grupo étnico, que passa a ser mais aceito e a predominar em diversas cidades. Deste modo, podemos dizer que, o surgimento de Mitani tornou possível que um grupo, antes marginalizado, fosse colocado em foco, ainda que de forma temporária.

\begin{abstract}
Ethnographic debates can contribute much to understand peoples from the ancient world. The Ancient Near East was characterised by the predominance of Semitic and, in less quantity, Indo-European people. However, these were not the only groups living there. This paper, thus, aims to present Hurrians through a historical and historiographical survey based on ethnicity. For years, the Hurrians lived in the fringes of the Near Eastern society, but they were able to keep their ethnic elements. In the Second Millennium BCE, those ethnic elements were fortified and widespread due to the Mitannian Kingdom. With Mitanni and the unification of the Hurrian groups, the Hurrian ethnic elements were accepted by others. In this paper, I present a discussion about ethnographic studies, both in terms of theory and its application to the case of Hurrians, aiming to better understand the dispersal and the identity of Hurrian groups.

Keywords: Hurrian, Mitanni, ethnicity, Ancient Near East.
\end{abstract}

\title{
REFERÊNCIAS
}

\section{Documentação}

BECKMAN, Gary M. Hittite Diplomatic Texts. Atlanta: Scholars Press, 1996. GREENSTEIN, Edward L.; MARCUS, David. The Akkadian Inscription of Idrimi. Journal of the Ancient Near Eastern Society (JANES), 8, 1976, pp. 59-96.

KUHRT, Amiélie. The Ancient Near East c. 3000-330 BC. Londres: Routledge, v.1, 1995.

PARDEE, Dennis. The Kirta Epic (1.102). In: HALLO, William W. (ed). The Context of Scripture. Canonical Compositions from the Biblical World. Leiden: Brill, v. 1., 2003, pp. 333-343.

PRITCHART, James B. Ancient Near Eastern Texts. Relating to the Old Testament. Princeton: Princeton University Press, 1969.

VAN DEN HOUT, T. P. J. The Proclamation of Telipinu (1.76). In: HALLO, William W. (ed). The Context of Scripture. Canonical Compositions from the Biblical World. Leiden: Brill, v. 1,, 2003, pp. 194-198. 
Bibliografia

BERKOOZ, Moshé. The Nuzi Dialect of Akkadian: Orthography and Phonology.

Language, vol. 13, n. 1, Language Dissertation No. 23, 1937, pp. 5-64.

BIENKOWSKI, Piotr; MILLARD, Alan. Dictionary of the Ancient Near East.

Londres: British Museum Press, 2000.

BRYCE, Trevor. Letters of the Great Kings of the Ancient Near East. The royal Correspondence of the Late Bronze Age. Nova York: Routledge, 2014.

BUCCELLATI, Giorgio. When Were the Hurrians Hurrian? The Persistence of Ethnicity in Urkesh. In: ARUZ, Joan; GRAFF, Sarah B.; RAKIC, Yelena (eds). Cultures in Contact. From Mesopotamia to the Mediterranean in the Second Millennium B.C. Nova York: Yale University Press, 2013, pp. 84-95.

BUCCELLATI, Giorgio. The Semiotics of Ethnicity: The Case of Hurrian Urkesh. In: FINCKE, J. Festschrift für Gernot Wilhelm anläßlich seines 65 Geburtstages am 28. Januar 2010. Dresden: ISLET, 2010, pp. 79-90.

CANCIK-KIRSCHBAUM, Eva; BRISCH, Nicole; EIDEM, Jesper (eds). Constituent, Confederate and Conquered Space. The Emergence of the Mittani State. Berlim: De Gruyter, 2014.

COLINS, Paul. From Egypt to Babylon: the International Age $1500-500$ BC. Cambridge: Harvard University Press, 2008.

ESTEVEZ, María de la Paz. La conquista de Toleto em 1085. Génesis y desarrollo de uma frontera a través de sus fuentes. In: NEYRA, Andrea V. \& RODRÍGUEZ, Gerardo (dirs.). Qué implica ser medievalista? Práticas y reflexiones en torno del historiador. Mar del Plata: Universidad de Mar del Plata, Sociedad Argentina de Estudos Medievales, 2012, v.2. pp. 23-43.

FREU, Jacques. Histoire du Mitanni. Paris: L'Harmattan, 2003.

GARELLI, Paul. O Oriente Próximo Asiático: das origens às invasões dos povos do mar. São Paulo: Pioneira, EDUSP, 1982.

GELB, Ignace J. Hurrians and Subarians. Chicago: The University of Chicago Press, 1973.

GOETZE, Albrecht. On the Chronology of the Second Millennium B. C. (Concluded). Journal of Cuneiform Studies - JCS. v. 11, n. 3, 1957.

HAAS, Volkert; WILHELM, Gernot. Hurritische und Luwische Riten aus Kizzuwatna. Neukirchen-Vluyn: Erziehungsvereins GmbH, 1974.

JAROL, RichardE. A Reconstruction of the Contributions of Mitanni to the Ancient Near East. Theses and Dissertations (Comprehensive). 1373, 1986. Disponível em: http://scholars.wlu.ca/etd/1373

JENKINS, Richard. Rethinking Ethnicity. Arguments and Explorations. Londres: SAGE Publications Ltd, 1998.

LIVERANI, Mario. Antigo Oriente. História, Sociedade e Economia. São Paulo: Edusp, 2016.

LION, Brigitte. Nuzi, Une Ville Du Monde Hourrite. HALUKA, Paris, n.3, 02/1998. Disponível em: http://y.deliyannis.free.fr/hatti/articles.php?id=hlk 33 
MARTINO, Stefano de. The Mittani State: The formation of the Kingdom of Mittani. In: CANCIKKIRSCHBAUM, Eva; BRISCH, Nicole; EIDEM, Jesper (eds).

Constituent, Confederate and Conquered Space. The Emergence of the Mittani State. Berlim: De Gruyter, 2014.

NOVÁK, Mirko. Mittani Empire and the Question of Absolute Chronology: Some

Archaeological Considerations. In: BIETAK, M.; CZERNY, E. The Synchronisation

of Civilizations in the Eastern Mediterranean in the Second Millenium B.C. Wien:

Proceedings of the SCIEM 2000 - 2ndEuro Conference, 2007, pp. 389 - 401.

PARADISE, Jonathan. Marriage Contracts of Free Persons at Nuzi. Journal of Cuneiform Studies, vol. 39, n. 1, 1987, pp. 1-36.

PINTO, Otávio Luiz Vieira. Integrating Magna Dacia. A Narrative Reappraisal of Jordanes. Tese de Doutorado. Leeds: University of Leeds. School of History, 2016. PODANY, Amanda H. Brotherhood of Kings. How international relations shaped the Ancient Near East. Nova York: Oxford University Press, 2010.

POUTIGNAT, Philippe; STREIFF-FENART, Jocelyne. Teorias da Etnicidade. São Paulo: Editora Unesp, 2011.

ROUX, Georges. Ancient Iraq. Londres: Penguin, 1992.

SCHNEIDER, Thomas. Foreigners in Ancient Egypt: Archaeological Evidence and Cultural Context. In: WENDRICH, W (ed.). Egyptian Archaeology. Oxford: Blackwell 2010, pp. 143-163.

SCOVILLE, Priscila. Queremos nos amar como irmãos: uma análise historiográfica das cartas de Amarna e das relações entre Egito e Mitani entre c. 1390 - 1336 AEC. Dissertação de Mestrado. Curitiba: UFPR, 2017.

STEIN, Diana L. Khabur Ware and Nuzi Ware: Their Origin, Relationship, and Significance. Monographic Journals of the Near East. Assur 4/1, 1984.

SUBARIAN. English Oxford Living Encyclopedia. Disponível em: https:// en.oxforddictionaries.com/definition/subarian

URARTIAN language. Encyclopædia Britannica. 02 de Novembro de 2015. Disponível em: https://www.britannica.com/topic/Urartian-language.

VAN DE MIEROOP, Marc. A History of the Ancient Near East ca. 3000-323

BC. Oxford: Blackwell, 2007.

VAN SOLDT, Wilfred. The use of Hurrian Names at Ugarit. Ugarit-Forschungen, 35, 2002, pp. 681-707.

VON DASSOW, Eva. Levantine Polities Under Mittanian Hegemony. In: CANCIKKIRSCHBAUM, Eva; BRISCH, Nicole; EIDEM, Jesper (eds). Constituent, Confederate and Conquered Space. The Emergence of the Mittani State. Berlim: De Gruyter, 2014.

WEST, M. L. The Babylonian Musical Notation and the Hurrian Melodic Texts. Music \& Letters, v. 75, n. 2, maio, 1994, pp. 161-179.

WILHELM, Gernot. The Hurrians. Warminster: Aris and Phillips Ltd, 1989. 